Military Technical College

Kobry El-Kobbah, Cairo, Egypt

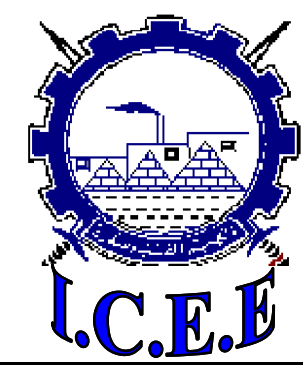

CE-4 $5^{\text {th }}$ International Conference on

Chemical \& Environmental

Engineering

\title{
REGENERATION OF SPENT ACTIVE CARBON USED IN WATER TREATMENT OPERATIONS BY DOMESTIC MICROWAVE OVEN
}

\author{
Makram M.Elwany*, Mohammad K.Abdel- Megeed* Ashraf M. Soltan* \\ and Ahmad A. Baraka*
}

\begin{abstract}
In this work the regeneration of spent granular active carbon saturated with phenol was studied in an aqueous solution by using domestic microwave oven, different factors have been studied such as microwave power level, $\mathrm{pH}$ of the solution, weight of the regenerated active carbon, volume of the regenerated solution, number of adsorption and regeneration cycles. It was found that, for the same power level, as the time of exposure increases, the regeneration efficiency increases. As, The microwave oven power increase from 160 to $800 \mathrm{~W}$, the regeneration efficiency increase from 60 to $90 \%$ after $1.5 \mathrm{~min}$ of radiation time, during the regeneration process the $\mathrm{pH}$ of the solution increase from about 6.03 to 7.15 , after $4-5$ adsorption/regeneration cycles the adsorption efficiency falls down from 90 to $55 \%$.
\end{abstract}

\section{Keywords}

Regeneration, adsorption, desorption, microwave, active carbon, phenol removal. 


\section{INTRODUCTION}

Activated carbons had become one of the most effective adsorbents for the removal of a wide variety of pollutants from both aqueous and gaseous environment [1]. because of their high adsorption capacity, fast adsorption process and the ability for regeneration. Some of the most important uses of activated carbon are air pollution control, solvent recovery, food processing, chemical and pharmaceutical industries, wastewater and water treatment processes (i.e. purification of drinking water) [2].

Microwave irradiation (MW) is an effective method for regeneration due to its ability for molecular level heating that leads to homogeneous and quick thermal reactions [3]. Several works make use of this method, in addition, there is no evidence that his technique can damage the carbon, although it may change its pore distribution to some extent[4]. The main advantages overcoming thermal regeneration techniques (steam or inert gas) which involve high energy consumption and reduction of adsorption capacity (5-15\%), chemical regenerations which require subcritical or supercritical conditions (large investment cost) and biological regenerations that are only effective to the biodegradable substances. Thus, a widespread and great progress in this area can be expected in the future [5].

Phenols belong to a group of common environmental contaminants. There are many industrial sources for such contaminants as oil refineries, coal gasification sites, petrochemical units, etc Which generate large quantities of phenols .Besides, phenolic derivatives are widely used as intermediates in the synthesis of plastics, dyes, pesticides, insecticides, paper, pulp and dye manufacturing. These contaminants, even at low concentrations, can cause unpleasant taste and odor of drinking water and most of these compounds are recognized as toxic carcinogens [6].Different methods designed to remove phenol from aqueous media have been proposed which include: aerobic and anaerobic biodegradation, oxidation by ozone [6]. And uptake by ion exchange resins, etc.

However, adsorption by activated carbon is best and most frequently used method. The relative advantages of adsorption over other conventional advanced treatment methods are: it can remove both organic as well as inorganic constituents even at very low concentrations, it is relatively easy and safe to operate, both batch and continuous equipment can be used, no sludge formation and frequently the adsorbent can be regenerated and used again. Moreover, the process is economical because it requires low capital cost and there are abundant lowcost materials available to produce active carbon from it [7]. The regeneration processes are very important to extra cost effect the whole task.

In this work, the regeneration of GAC in aqueous media using domestic microwave set under different operating conditions is investigated to evaluate its adsorption efficiency after successive regeneration cycles and to ensure its practical feasibility.

\section{Experimental}

\subsection{Materials}

Phenol-adsorption on active carbon was firstly performed to assist the adsorption behavior. Next the phenol-removal processes by MW were performed to evaluate the regeneration process. The materials used in this study are: crystalline grade phenol (98\% purity), bidistilled water and commercial granular active carbon, having (specific surface area 830 $\mathrm{m}^{2} / \mathrm{g}$, particle size from 1500 to $250 \mu \mathrm{m}$, bulk density $=447 \mathrm{Kg} / \mathrm{m}^{3}$ and ash content $4.22 \%$ ). A concentrated stock solution of phenol (1000 ppm) was prepared and diluted solutions for 
samples were prepared from this stock using bi-distilled water. Prior use, GAC was washed by bi-distilled water to remove any foreign materials and impurities. It is then dried at $110{ }^{\circ} \mathrm{C}$ for $24 \mathrm{~h}$ and stored in desiccators for planed experiments.

\subsection{Phenol adsorption and kinetics}

Kinetics and isotherm experiments were performed to assess the behavior of this specific GAC for the adsorption of phenol.

Kinetic study of phenol adsorption process on GAC was carried out by placing a known quantity of the adsorbent, $0.2 \mathrm{~g}$, in a $250 \mathrm{ml}$, conical flask, containing $100 \mathrm{ml}$ of an aqueous solution of phenol with concentration $140 \mathrm{ppm}$. Absorption was performed by batch method using shaker (STUART SCIENTIFIC ORBITAL SHAKER SO1) at $120 \mathrm{rpm}$. Residualphenol concentration was determined with time, 60 minutes interval till equilibrium, by measuring the absorbance at $\lambda_{\max }=270 \mathrm{~nm}$ using (SHIMADZU UV-160 recording spectrophotometer).

The concentration was calculated from a pre-determined calibration curve. Adsorption capacity was calculated according to $Q=\left(C_{\mathrm{i}^{-}} C_{\mathrm{t}}\right) V / W$; where $C_{\mathrm{i}}$ and $C_{\mathrm{t}}$ are the initial and timed concentrations ( $\mathrm{mg} / \mathrm{l})$, respectively, of phenol in solution; $V$ is the volume (l), and $W$ is the weight $(\mathrm{g})$ of the adsorbent. Data was collected based on triplicate measurements. To determine the rate constant of phenol-adsorption on GAC, pseudo first order model was employed and its linear formula is as follows [8]:

$\log \left(q_{\mathrm{e}}-q_{\mathrm{t}}\right)=\log q_{\mathrm{e}}-k t / 2.303$

Where $q_{\mathrm{e}}, q_{\mathrm{t}}, k$ and $t$ are adsorbed amount $(\mathrm{mg} / \mathrm{g})$ at equilibrium, adsorbed amount $(\mathrm{mg} / \mathrm{g})$ at time $t$, rate constant $\left(\mathrm{min}^{-1}\right)$ and time in (minutes), respectively.

\subsection{Adsorption isotherm}

Adsorption isotherm experiments were performed at ambient temperature of about $20{ }^{\circ} \mathrm{C}$, using sample dosages of $0.2 \mathrm{~g} / 100 \mathrm{ml}$ aqueous solution of initial phenol concentrations 40, $60,80,120,140,160$ and $200 \mathrm{ppm}$. The conical flasks were shaken at $120 \mathrm{rpm}$. To ensure maximum adsorption, samples were left for 24 hours which was pre-determined to be sufficient to attain equilibrium. The maximum adsorption capacity of GAC used in this work was determined using Langmuir model [9]:

$1 / q_{\mathrm{e}}=1 / Q_{\mathrm{o}}+1 /\left(b Q_{\mathrm{o}} C_{\mathrm{e}}\right)$

where $q_{\mathrm{e}}(\mathrm{mg} / \mathrm{g})$ is the adsorbed amount at equilibrium, $C_{\mathrm{e}}(\mathrm{mg} / \mathrm{l})$ is the concentration at equilibrium. $Q_{\mathrm{o}}(\mathrm{mg} / \mathrm{g})$ and $b(\mathrm{l} / \mathrm{mg})$ are the maximum adsorption capacity and adsorption affinity, respectively.

\subsection{Microwave regeneration}

Regeneration of the spent GAC, was carried out in a domestic microwave set (MW hot point model 6640) of maximum output power of $800 \mathrm{~W}$ at frequency $2400 \mathrm{MHz}$ with adjustable power settings and time programming. Each GAC sample, $0.2 \mathrm{~g}$, was placed in a $250 \mathrm{ml}$, flatbottomed flask, containing $100 \mathrm{ml}$, distilled water, and then exposed to microwave irradiation under controlled operating conditions. The power level of this set is as follows: PL1 $=160 \mathrm{~W}$, PL2 $=320 \mathrm{~W}$, PL3 $=480 \mathrm{~W}$, PL4 $=640 \mathrm{~W}$ and PL5= $800 \mathrm{~W}$. For each PL, the effect of time 
was considered by measuring the absorbance of phenol-residue in the solution at different time intervals: $0.5,1,1.5,2,2.5$ and 3 minutes. It was always considered to avoid evaporation state. The process of adsorption and desorption was repeated 5 times, considering the same conditions, to determine the maximum efficient number of regeneration cycles.

\subsection{Monitoring the $\mathrm{pH}$ change}

The change in $\mathrm{pH}$ of the medium after regeneration, for the different PL and time conditions, with respect to regenerating media was determined using $\mathrm{pH}$ meter $(\mathrm{pH}-211$ microprocessor $\mathrm{pH}$ meter Hanna instruments).

\subsection{Volume of regeneration water}

To assess the economy of the regeneration process, the volume of bi-distilled water used for regeneration was varied to study this effect on the regeneration process. A series of volumes $(30,50,70,100 \mathrm{ml})$ were used for regeneration of $0.2 \mathrm{~g} \mathrm{GAC}$ saturated with phenol at PL5 and irradiation time 1.5 minute. Again the amount of phenol retained on GAC was determined using adsorption technique.

\subsection{Weight loss of regenerated GAC}

The loss in original weight of GAC sample due to successive regeneration cycles was investigated as a factor affecting the regeneration process. A laboratory scale experiment was designed to study this effect by subjecting one gram of GAC sample to a repetitive regeneration process for 4-5 cycles under operating conditions of PL5 and irradiation time 1.5 minute, the change in weight has been determined using a 4 digits analytical balance (Scaltec SBA 31).

\subsection{Characterization of fresh and regenerated GAC}

The specific surface area of fresh, exhausted and regenerated GAC was determined using the Micromeritics ASAP $2405 \mathrm{~N}$ adsorption analyzer by measuring nitrogen adsorption/desorption isotherms at $77.4 \mathrm{~K}$. IR spectra of the selected samples were recorded using Fourier-transform infrared spectroscopy technique (SHIMADZU FTIR-8400).

\section{Results and discussion}

\subsection{Phenol adsorption kinetics}

The time profile ( 8 hours) for phenol removal from water by $\mathrm{GAC}$, at $20^{\circ} \mathrm{C}$, is shown in Figure 1. It can be noticed that removal is smooth and continuous with time which suggest open pores texture of GAC and rate of adsorption can be suggested to be constant over this time range. The adsorption experiments were carried out under shaking conditions which limits the effect of film diffusion.

As shown in Figure 2, pseudo first-order kinetic model can be a reasonable candidate under this case. The relation is linear with correlation factor $R=0.974$ which indicate good confidence in data. The adsorption rate constant from this relation is $k=0.454 \mathrm{~min}^{-1}$ which is considered high enough in this type of application.

\subsection{Phenol adsorption isotherm}

Figure 3 shows the Langmuir adsorption isotherm at $20^{\circ} \mathrm{C}$. The relation is linear with correlation factor $R=0.970$ which indicate good confidence in data. The maximum capacity 
derived from equation is $\mathrm{Q}_{\mathrm{o}}=123.5 \mathrm{mg} / \mathrm{g}$ which is comparable with some related published values [10]. This suggests phenol monolayer adsorption on GAC and adsorption energy is the same for all sites.

It was found that phenol adsorption on activated carbon can be achieved following a complex interplay through three possible mechanisms: [11].

- $\pi-\pi$ dispersion interaction between the phenol aromatic ring and the delocalized $\pi$ electrons present in the aromatic structure of the graphite layers [12].

- Hydrogen bond formation [12].

- Electron donor- acceptor complex formation at the carbon surface where the oxygen of the surface carbonyl group acts as electron donor whiles the phenol aromatic ring being the acceptor [13].

However, to have a good idea about the mechanism of adsorption a several isotherm models have to be applied on the obtained data; these models can give a good suggestion about the main mechanism of phenol adsorption.

\subsection{Regeneration of spent GAC by Micro wave}

In the study, regeneration efficiency is defined as the percentage amount of phenol adsorbed in the second adsorption process (after regeneration) divided by the amount of phenol adsorbed by fresh active carbon. From Figure 4, the regeneration reached about $90 \%$ at PL5 for 1.5 minute irradiation. It is worth to mention that the regeneration efficiency (was reached to $97-99 \%$ ) as reported by $[14,15]$. however they apply a different technique by using microwave for regeneration of dry GAC in inert atmosphere.

Also, it is observed that as PL increases, the regeneration efficiency increases.

It is suggested that phenol molecules suffers from excessive local heating which leads to quick thermal decomposition. By MW, heat energy readily transformed into dipole rotation some present groups or space charge polarization (as some free electrons are facially distributed over carbon surface) [3, 5]. This in turn heats adsorbate, phenol, and causes its decomposition. The decomposition is also practically highly suggested from experimental observations. The measurement of supposed GAC-released phenol, by spectrometry, shows lower values of phenol compared to be expected which is calculated from the next adsorption process.

For each PL, the regeneration efficiency also increases with time. Again, this gives more duration for microwave to decompose the phenol. For PL4 and PL5, regeneration efficiency was not determined after 1.5 minute because of solution evaporation. Regeneration occurs within some minutes range. This is due to rapid heating of activated carbon by this technique. 


\subsection{The pH change with MW treatment}

Figure 5 presents the change in $\mathrm{pH}$ value of the solution, $\Delta \mathrm{pH}$, due to $\mathrm{MW}$ irradiation. This change increases with PL, i.e. it shows more alkalinity. Also, increase of time, for each PL, has the same effect. The maximum $\Delta \mathrm{pH}$ is 1.02 at PL5 and 1.5 minutes duration. The general trend in this figure follows, almost, the same trend of regeneration efficiency.

This change also suggests the decomposition mechanism mentioned earlier as this change emanates from a decomposition product not from phenol. This is confirmed by auxiliary experiment shows that GAC/water system does not give significant change in $\mathrm{pH}$ under considered PL studied. On the contrary, phenol/water system does give almost the same $\Delta \mathrm{pH}$ as for $\mathrm{phenol} / \mathrm{GAC} / \mathrm{water}$ system.

This is present in Figure 6 that shows the change in absorbance for phenol/water system after MW-irradiation at PL5and time 1.5 minutes. Table 1 gives data for the effect of MWirradiation at different PL and irradiation time. Consequently, it can be concluded that observed $\Delta \mathrm{pH}$ is due to phenol decomposition during regeneration process.

\subsection{The volume of regeneration water}

From the data recorded in Table 2, it is clearly noticed that the increase in volume from30$100 \mathrm{ml}$ of the water used in regeneration of GAC give only a slight increase of the Regeneration efficiency at PL5 and irradiation time 1.5 minutes.

\section{6 weight loss of regenerated GAC}

Figure 7 shows that the weight loss of GAC sample ranges from $2 \%$ to about $5 \%$ of the original weight after 5 regeneration cycles for PL5 and irradiation time 1.5 minutes. The weight loss during regeneration can be noticed as a black dusty layer on the surface of regeneration solution, this may be due to wear effect between GAC particles during MW irradiation.

\subsection{Characterization of fresh and regenerated GAC}

BET analysis gives the specific surface area for Fresh GAC is $830 \mathrm{~m}^{2} / \mathrm{g}$, exhausted $130 \mathrm{~m}^{2} / \mathrm{g}$, regenerated 1 cycle $680 \mathrm{~m}^{2} / \mathrm{g}$ regenerated 5 cycles $300 \mathrm{~m}^{2} / \mathrm{g}$.

This successive decrease in the specific area may be due to the permanent adsorption of a certain amount of phenol inside the pores and this phenomenon could suggest that a strong chemisorption mechanism has a considerable sharing in the overall adsorption process.

The IR spectra of the four samples of GAC were analyzed as follow: the appearance of bands at the region about $3448.5-3421.5 \mathrm{~cm}^{-1}$ refers to $(\mathrm{O}-\mathrm{H})$ stretching vibrations in the hydroxyl, carboxylic or phenolic groups, since the location of the hydrogen-bonded $\mathrm{OH}$ groups is usually in the range of $3200-3650 \mathrm{~cm}^{-1}[16,17]$. The band appears at $2854.5 \mathrm{can}$ be assigned to $\mathrm{C}-\mathrm{H}$ group stretching, which usually appear at $2800-3000 \mathrm{~cm}^{-1}$ for aromatic and aliphatic $\mathrm{C}-\mathrm{H}$ groups $[17,18]$.

The presence a bands in the region between $1635.5-1627.8 \mathrm{~cm}^{-1}$ has been observed by many earlier workers. It is known that olefinic $\mathrm{C}=\mathrm{C}$ stretching band is located at $1650 \mathrm{~cm}^{-1}$ and the absorption maximum may shift toward lower wave numbers when the $\mathrm{C}=\mathrm{C}$ bond is conjugated with another $\mathrm{C}=\mathrm{C}$ bond, an aromatic nucleus, or a $\mathrm{C}=\mathrm{O}$ bond. $\mathrm{In}$ fact, the $\mathrm{C}=\mathrm{C}$ stretching absorption frequently occurs at approximately $1600 \mathrm{~cm}^{-1}$ for carbonaceous materials [2].

The band located at about $1384.8 \mathrm{~cm}^{-1}$ could be attributed to $\mathrm{C}-\mathrm{H}$ deformation vibration in alkenes that frequently occurs at approximately $1381 \mathrm{~cm}^{-1}$ [16]. 
The appearance of bands between 1033.8 and $1037.6 \mathrm{~cm}^{-1}$ could be as-signed to $\mathrm{C}-\mathrm{O}$ stretching vibrations in phenolic and carboxylic groups [16], while The bands at $<700 \mathrm{~cm}^{-1}$ may refers to $\mathrm{C}-\mathrm{H}$ vibration[16,18].

the data mentioned above show the presence of both phenolic and carboxylic groups, with different portions in each individual sample while the determination of these portions are too difficult due to the qualitative nature of FTIR measurements. The effect of microwave irradiation on the surface chemistry of GAC may alter this functionality which may affect the contribution of different mechanisms of phenol adsorption suggested by literatures $[6,11,19$ This effect have not dealt in this work as it need a separate research which is intended to be performed in the future work.

\section{CONCLUSION}

Domestic microwave oven was used to study the regeneration of GAC after saturation with phenol in aqueous solution. The pre-step of adsorption reviled that pseudo first-order is a good model to represent kinetic adsorption of phenol on GAC. The adsorption rate constant was found to be $k=0.454 \mathrm{~min}^{-1}$. Langmuir adsorption isotherm at $20^{\circ} \mathrm{C}$ gives maximum adsorption capacity as $Q_{\mathrm{o}}=123.5 \mathrm{mg} / \mathrm{g}$. For regeneration of GAC by micro wave, it is suggested that the regeneration efficiency increases with power level and time up to certain limit. The $\mathrm{pH}$ of the solution was increased by approximately one degree on the $\mathrm{pH}$ scale and this is may be due to the decomposition of the phenol by the micro wave radiation. It was found that, increase in volume of the water used in regeneration of GAC give a slight increase of the regeneration efficiency. The GAC weight loss due to regeneration cycles was found to be in the range of $2-5 \%$. BET analysis elucidates that the specific surface area decrease with the regeneration cycles.

\section{References}

[1] Helena jankowska, andrzej swiatkowski, jerzy choma, active carbon, elles horwood, new york London Toronto Sydney Tokyo Singapore.

[2] Min-Woo Junga, Kyu-Hong Ahna, Yonghun Leea, Ki-Pal Kimb, Jae-Seong Rheec, Jung Tae Parkd, Ki-Jung Paengb, Adsorption characteristics of phenol and chlorophenols on granular activated carbons(GAC),Microchemical Journal 70(2001)123-131[ 2]

[3] Xitao Liu, Xie Quan, Longli Bo, Shuo Chen, Yazhi Zhao, Simultaneous pentachlorophenol decomposition and granular activated carbon regeneration assisted by microwave irradiation, carbon 4 (2004) 415-422

[4] C.O. Ania, J.B. Parra, J.A. Mene'ndez, J.J. Pis ,Effect of microwave and conventional regeneration on the micro porous and meso porous network and on the adsorptive capacity of activated carbons, Micro porous and Meso porous Materials 85 (2005) 7-15

[5] Foo Keng Yuen, B.H. Hameed, Recent developments in the preparation and regeneration of activated carbonsby microwaves, journal of Advances in Colloid and Interface Science 149 (2009) $19-27$.

[6] A. Da browski, P. Podkos cielny, Z. Hubicki, M. Barczak, Adsorption of phenolic compounds by activated carbon - a critical review, chemosphere 58 (2005) 1049-1070

[7] Kaustubha Mohanty ,D.Dasb, M.N. Biswas, Adsorption of phenol from aqueous solutions using activated carbons prepared from Tectona grandis sawdust by $\mathrm{ZnCl} 2$ activation chemical engineering journal 115 (2005)121-131.

[8] M.sekar,v.sakthi,s.renjaraj,kinitics and equilibrium adsorption study of lead (П) on activated carbon prepared from coconut shell, j. colloid interf.sci.279(2004)307-313 
[9] Langmuir I, j.amer. chem. soc., 37(1915) p. 1139.

[10] Keith K.H. Choy, Gordon McKay, John F. Porter, Sorption of acid dyes from effluents using activated carbon, Resources, Conservation and Recycling 27 (1999) 57-71.

[11] J.M. Valente Nabais a, J.A. Gomes a, Suhas a , P.J.M. Carrotta , C. Laginhas a, S. Roman b, Phenol removal onto novel activated carbons made from lignocellulosic Precursors: Influence of surface properties, journal of hazardous materials 167(2009) $904-910$.

[12] R.W.Coughlin, F.S. Ezra, Roleof surface acidity in the adsorption of organic pollutants on the surface of carbon environ, science technology 2(4) (1968)291-297.

[13] J.S.Mattson ,H.B .Mark Jr .,M.D.Malbin, W.J.Weber Jr., J.C.Crittenden, surface chemistry of activate carbon : specific adsorption of phenols, journal of Colloid and Interface Science 31(1) (1969) $116-130$

[14] XieQuan, Xitao liu , Longli Bo ,Shuo Chen, Yazhi Zhao, xinyi Cui,Regeneration of acid orange 7-exhausted granular activated carbons with micro wave irradiation, water research 38(2004) 4484-4490.

[15] Haque, K.E.,Kondos,P.D.,MacDonal,R.J.C, microwave activation of carbon,US Patent CA2008242.

[16] Yifeng Wang, Huizhen Gao, Rakesh Yeredla, Huifang Xu, Mike Abrecht Control of pertechnetate sorption on activated carbon by surface functional groups Journal of Colloid and Interface Science 305 (2007) 209-217

[17] Ulker Beker , Batchimeg Ganbold, Halil Dertli , Dilek Duranog Adsorption of phenol by activated carbon: In uence of activation methods and solution $\mathrm{pH}$, Energy Conversion and Management 51 (2010)235-240.

[18] Pretsch Cherc Seibl Simon, tables of spectral data determination of organic compounds, springer-verlag ,berlin Heidelberg new york Tokyo 1983.

[19] Issa I. Salame and Teresa J. Bandosz, Role of surface chemistry in adsorption of phenol on activated carbons, Journal of Colloid and Interface Science 264 (2003) 307-312.

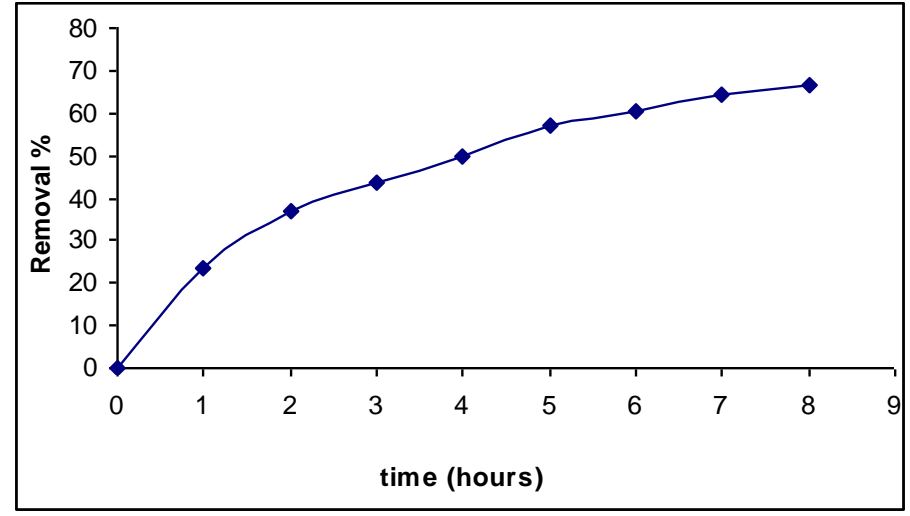

Figure 1: Removal percentage of phenol with time at $20^{\circ} \mathrm{C}$ 


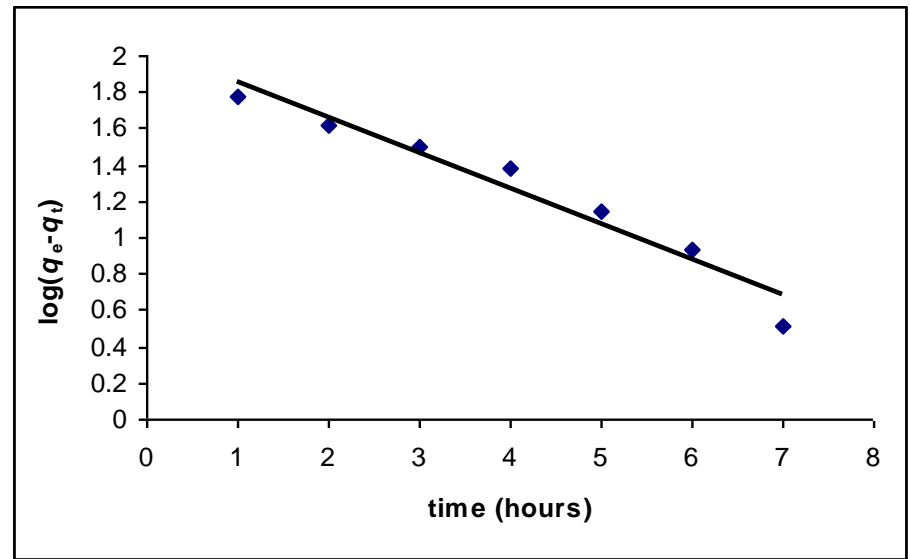

Figure 2: Pseudo first-order plot of phenol adsorption on GAC at $20^{\circ} \mathrm{C}$

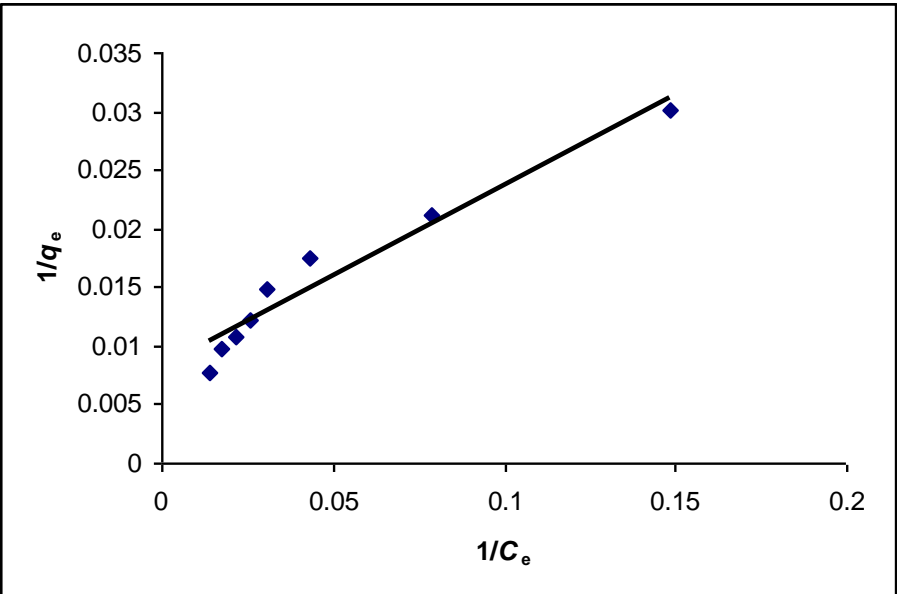

Figure 3: Langmuir adsorption isotherm of phenol on GAC at $20^{\circ}$

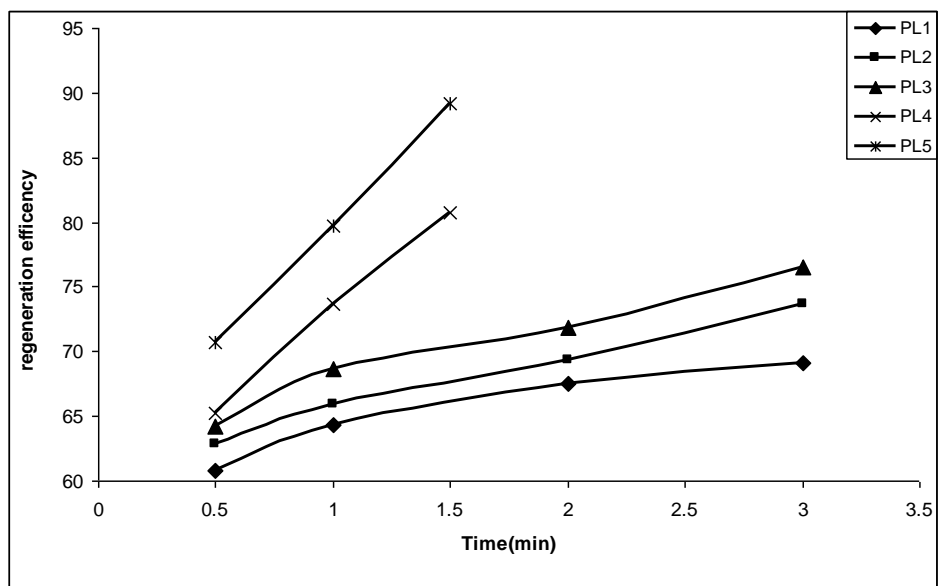

Figure 4: Regeneration efficiency of GAC saturated with phenol at different power levels 


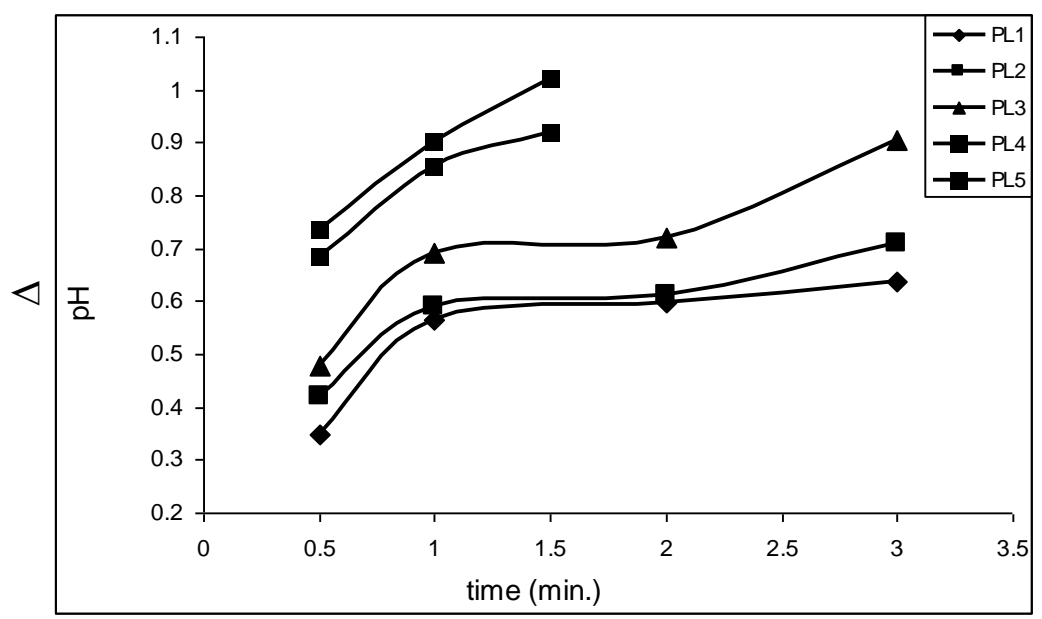

Figure 5: change in $\mathrm{pH}$ with microwave irradiation time and different power levels.

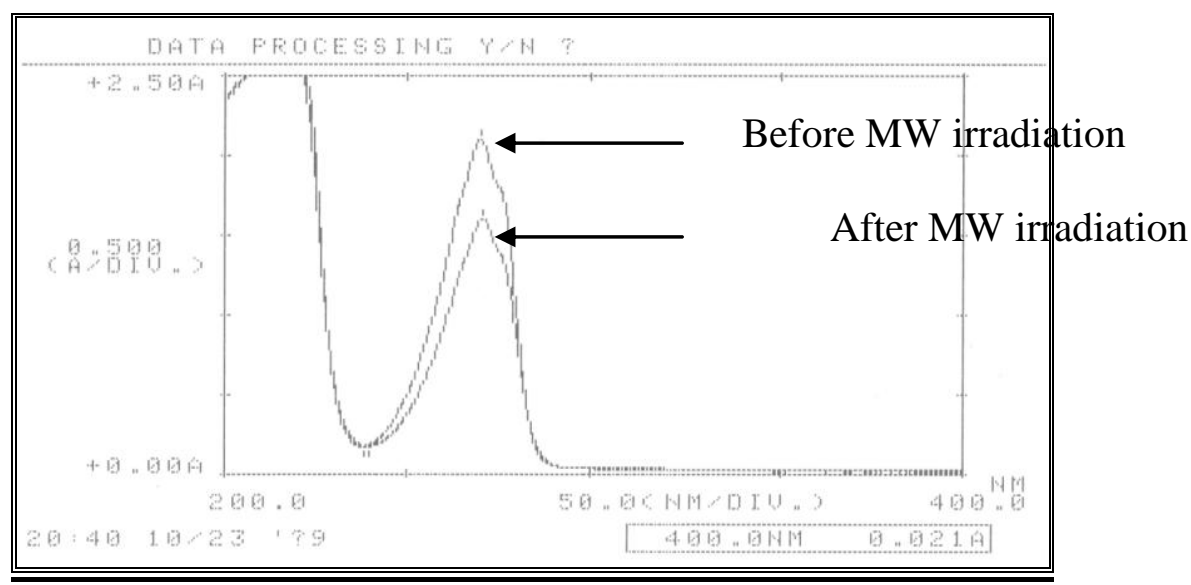

Figure 6: Change in UV absorbance before and after irradiation of phenol/ water system at PL5 and time 1.5 minutes

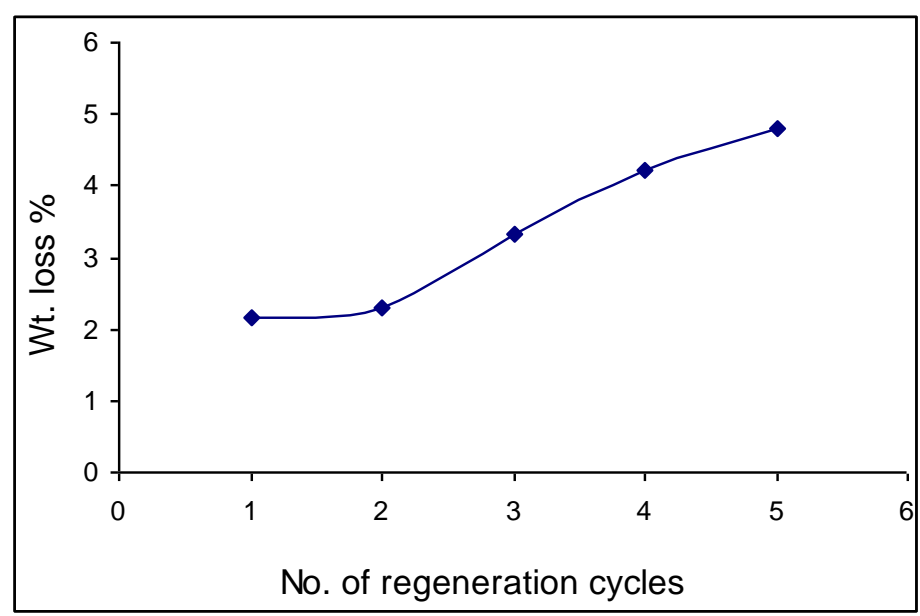

Figure 7: GAC Wt. loss\% with respect to No. of regeneration cycles at PL5 and irradiation time 1.5 minutes. 

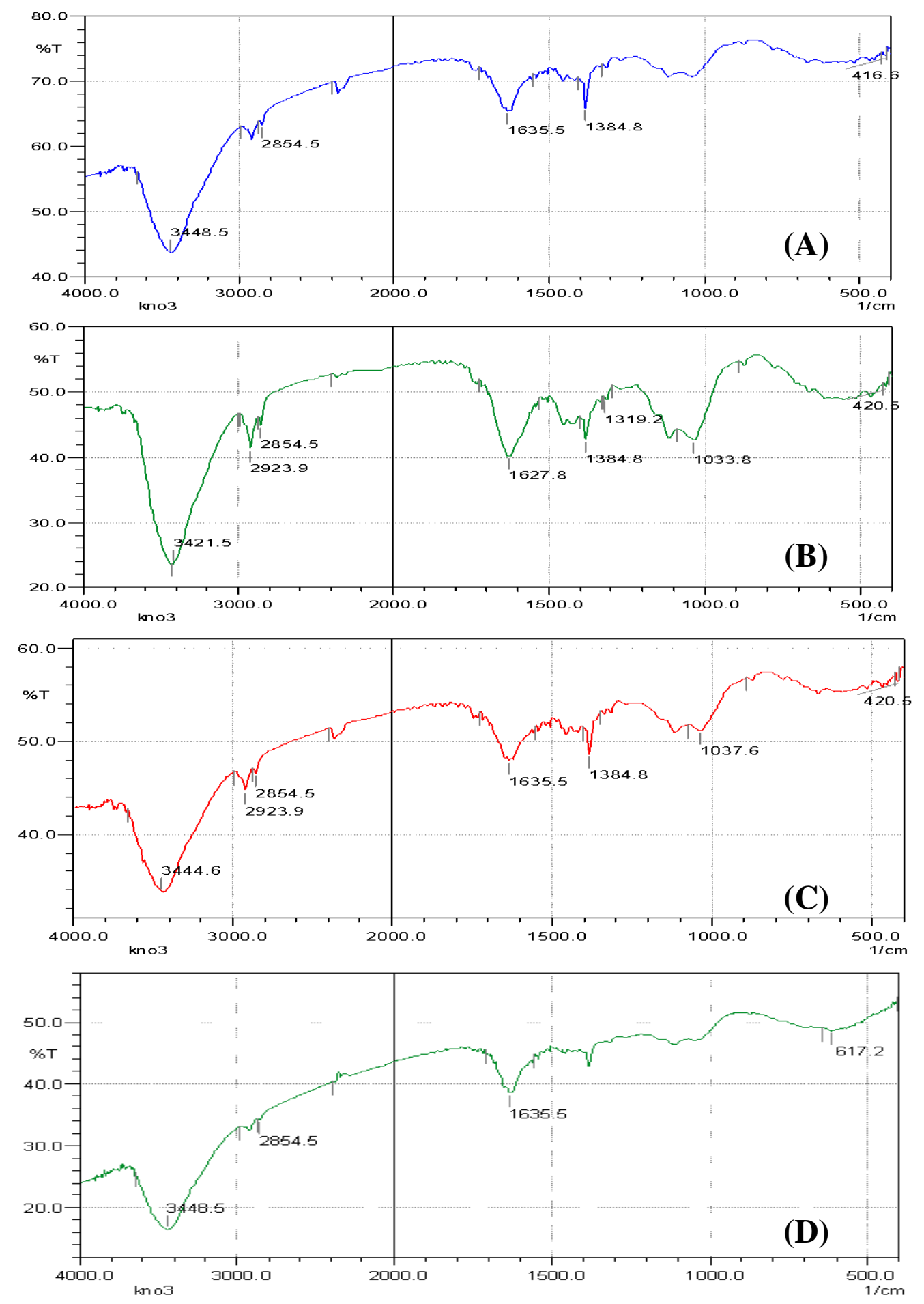

Figure 8: IR spectra for (A) Fresh GAC, (B) GAC saturated with Phenol, (C) GAC Regenerated at power level [1] and (D) GAC Regenerated at power level [5] 
Table 1: Change in $\mathrm{pH}$ for phenol/ water system due to MW irradiation

\begin{tabular}{|c|c|c|c|c|c|}
\hline System & Power level & Time (min) & $\mathrm{pH}$ before & $\mathrm{pH}$ after & $\Delta \mathrm{pH}$ \\
\hline \multirow{4}{*}{ phenol/water } & 1 & 3 & 6.59 & 7.21 & 0.62 \\
\cline { 2 - 6 } & 2 & 3 & 6.54 & 7.26 & 0.72 \\
\cline { 2 - 6 } & 3 & 3 & 6.59 & 7.48 & 0.89 \\
\cline { 2 - 6 } & 4 & 1.5 & 6.56 & 7.49 & 0.93 \\
\cline { 2 - 6 } & 5 & 1.5 & 6.49 & 7.59 & 1.1 \\
\hline
\end{tabular}

Table 2: Change in volume of regeneration water with respect to regeneration efficiency

\begin{tabular}{|c|c|c|c|c|}
\hline Sample No. & Volume $(\mathrm{ml})$ & PL & Time(min.) & Regeneration efficiency \\
\hline 1 & 30 & 5 & 1.5 & 88.02 \\
\hline 2 & 50 & 5 & 1.5 & 88.99 \\
\hline 3 & 70 & 5 & 1.5 & 89.48 \\
\hline 4 & 100 & 5 & 1.5 & 89.80 \\
\hline
\end{tabular}


Military Technical College

Kobry El-Kobbah, Cairo, Egypt

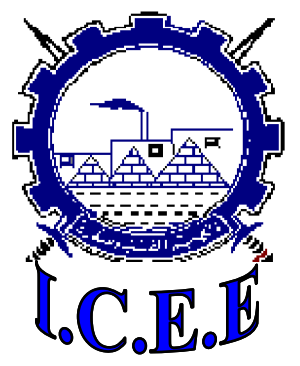

$5^{\text {th }}$ International Conference on

Chemical \& Environmental Engineering 25 - 27 May, 2010. 